\title{
Ultra High Transmission Capacity of Undersea Optical Fiber Cables for Upgrading UW-WDM Submarine Systems
}

\author{
Ahmed Nabih Zaki Rashed \\ Electronics and Electrical Communication Engineering Department, Faculty of Electronic Engineering, \\ Menoufia University, Menouf, 32951, Egypt
}

\begin{abstract}
This paper has proposed ultimate optical transmission of ultra multi transmission channels huge submarine cables has been investigated under different depth conditions. Conventional forward Raman amplification technique is considered taking into account the reduction of the four wave mixing (FWM). The double impact of both ambient temperature and pressure effects are also investigated. The transmission technique is studied namely Soliton propagation technique. As well as two multiplexing methods are considered in the design namely ultra wide wavelength division multiplexing (UW-WDM) and ultra-wide space division multiplexing (UW-SDM). Based on experimental data, both the deep ocean water temperature and pressure are tailored as functions of the water depth. The product of the transmitted bit rate and the repeater spacing is processed over wide ranges of the affecting parameters.
\end{abstract}

Keywords Four Wave Mixing, Submarine Systems, Multiplexing Techniques, Soliton Propagation and Undersea Depths

\section{Introduction}

To realize a long-haul high bit rate $1.5 \mu \mathrm{m}$ undersea lightwave transmission system, the solution is to develop both a single longitudinal mode laser diode (LD) and dispersion shifted fiber to negate the effect of large chromatic dispersion in conventional fiber at $1.5 \mu \mathrm{m}$ [1]. In developing submarine optical fiber cable for $1.5 \mu \mathrm{m}$ operation, the ncreased sensitivity to bending loss during cabling and laying operations must be carefully considered. In addition a high accuracy measurement technique of optical loss and chromatic dispersion for the purpose of investigating long-length and high-bit-rate transmission potential must be established[2]. Compared with the conventional coaxial undersea cable systems, an optical fiber undersea cable system has a great technical and economical advantage. It is also suitable for digital transmission. Coaxial undersea cable systems have been used as one of the major transmission systems in international telecommunication networks over the past 25 years, and its channel capacity has rapidly been increased about ten times per decade with the growth in overseas traffic. However, this system has nearly reached a limit in its ability to increase the capacities of long-haul

* Corresponding author:

ahmed_733@yahoo.com (Ahmed Nabih Zaki Rashed)

Published online at http://journal.sapub.org/ijnc

Copyright (C) 2011 Scientific \& Academic Publishing. All Rights Reserved transoceanic systems from the standpoint of reliability and economy, although additional growth may be permitted with short-haul cable systems. On the other hand, the research and development on optical fiber communication systems progressed remarkably in the 1970's, and a number of systems using $0.85 \mu \mathrm{m}$ wavelength have already been put into commercial services. Recently, the experimental systems using long wavelength and single-mode fibers are now actively being developed worldwide[3].

The first undersea lightwave cable system installed in the Pacific Ocean was the third trans-pacific cable (TPC-3) system. The characteristic features of the TPC-3 system were $1.3 \mu \mathrm{m}$ signal wavelength, about $50 \mathrm{~km}$ repeater spacing, and the transmission bit rate of $280 \mathrm{Mbit} / \mathrm{sec}$. The second system was the fourth trans-pacific cable (TPC-4) system and the technical features of this system were 1.55 $\mu \mathrm{m}$ signal wavelength, about $120 \mathrm{~km}$ repeater spacing, and the transmission bit rate of $560 \mathrm{Mbit} / \mathrm{sec}$. Both systems were using $3 \mathrm{R}$ optical repeaters for the optical signal transmission. This type of the optical repeater had three functions as retiming, reshaping, and regenerating of the optical signal, and these functions were realized by the monolithically integrated electrical circuit At present there are several plans to install the lightwave cable system employing optical amplifiers[4]. Until the middle of 1990's, the fifth trans-Pacific cable network (TPC-5 CN) system was installed in the Pacific Ocean, and the twelfth and the thirteenth trans-Atlantic cable (TAT-12, 13) was installed in the 
Atlantic Ocean. These systems have the line bit rate of 5 $\mathrm{Gbit} / \mathrm{sec}$ that is about eight times as much as that of the latest undersea systems using 3R repeaters[5]. The design of submarine cables is shaped by the submarine environment, which is very different than the environment for terrestrial cables. The underwater environment is very stable, very extreme, and very hard to reach. Repairs of undersea cables are difficult and expensive, so systems are designed to operate without service for long periods. Specifications usually call for no more than two underwater repairs in a cable's nominal 25 year life time, and the target is no repairs. Electrical power must be transmitted from the cable termination points on land, so power is at a premium. Early systems used repeaters, but since the mid-1990s all submarine cables have used only optical amplifiers underwater[6]. Full "three-R" regeneration, reshaping and retiming pulses as well as reamplifying them is done only at the cable termination points on shore. For intercontinental cable systems spanning thousands of kilometers, this imposes very stringent requirements on the levels of noise, dispersion, and nonlinear effects in the transmitting fiber and the optical amplifiers. The fiber-optic cables used in submarine systems are highly specialized, with fibers embedded deep in the core of a pressure-resistant structure. The outer layers of deep-sea cables are medium-density polyethylene. Heavy metallic armor covers the polyethylene in shallow-water cables, which are buried to protect them from fishing trawlers and ships' anchors-the undersea counterparts of backhoes. If undisturbed, the cable structure should withstand intense pressures and exclude salt water for decades[7]. Optical amplifiers are mounted inside pressure-resistant cases originally developed to house repeaters. They are built into the cable but are larger in diameter, so at first glance they resemble a rabbit swallowed by a python. Submarine cable developers still call these cases "repeaters," but don't be fooled-repeaters have not been used on submarine cables for several years (although the repeaters on old cables have not been replaced). Submarine cables fall into two broad classes, unrepeatered and repeatered in the world of submarine cables, these terms define whether or not the system includes optical amplifiers with their pump lasers in the same underwater housing as the optical amplifier. Underwater pump lasers mark a key dividing point because they are electronic components subject to failure, and because they require electrical power to be transmitted through the cable. These two types can be further subdivided according to the distance they span and their configuration, but we will concentrate on the basic categories[8].

In the present study, we have investigated submarine cables to meet extremely tough requirements. Their transmission capacity should be as high as possible, because the cables are costly to make, lay, and operate. The cable, and any optical amplifiers or repeaters, must withstand harsh conditions on the bottom of the ocean for a design life of multi years. As well as we have modeled the integrated problem of optical undersea fiber cable, taking into account the effect of depth. The integrated problem is the product of the transmitted bit-rate and the repeater spacing where the following multiplexing technique is employed such as soliton propagation technique, two ultra multiplexing arrangements [ultra wide wavelength division multiplexing (UW-WDM) and ultra wide space division multiplexing (UW-SDM)], where ultra multi channels are transmitted through multi optical fiber links. Moreover forward Raman amplification method is employed, and the problem of four-wave mixing is reduced by increasing the channel spacing.

\section{System Modeling Analysis}

Based on reported data of[9], the pressure-dependent Sellemeier coefficients and material dispersions for silica fiber glass will be cast under the form:

$$
\mathrm{n}^{2}(\lambda, T, P, x)=n^{2}(\lambda, T, x) f(\lambda, P)
$$

Where $\mathrm{n}$ is the core refractive index, $\lambda$ is the optical wavelength, $\mathrm{T}$ is the ambient temperature, $\mathrm{P}$ is the pressure in Mega Newton $/ \mathrm{m}^{2}$, and $\mathrm{x}$ is the mole fraction of $\mathrm{GeO}_{2}$, i.e. percentage of germania-doped silica fiber in Ref.[10] cast the following:

$$
n^{2}(\lambda, p)=A+\frac{B \lambda^{2}}{\lambda^{2}-C}+\frac{D \lambda^{2}}{\lambda^{2}-E}
$$

With: $\mathrm{A}_{\mathrm{s}}=1.29552+9.86385 \times 10^{-6} \mathrm{P}+0.544763 \times 10^{-8}$ $\mathrm{P}^{2}, \mathrm{~B}_{\mathrm{s}}=0.809872+42.0899 \times 10^{-6} \mathrm{P}-1.71823 \times 10^{-8} \mathrm{P}^{2}, \mathrm{C}_{\mathrm{s}}=$ $1.07945 \times 10^{-2}-0.56693 \times 10^{-8} \mathrm{P}+0.894313 \times 10^{-10} \mathrm{P}^{2}, \mathrm{D}_{\mathrm{s}}=$ $0.917151+38.7911 \times 10^{-6} \mathrm{P}-1.13552 \times 10^{-8} \mathrm{P}^{2}$, and $\mathrm{E}_{\mathrm{s}}=$ 100.0. For Plastic fiber cable, the coefficients will be cast as: $\mathrm{A}_{\mathrm{P}}=2.5432+8.2132 \times 10^{-5} \mathrm{P}+0.1953 \times 10^{-6}, \mathrm{~B}_{\mathrm{P}}=0.8321+$ $2.4567 \times 10^{-4} \mathrm{P}-23.986 \times 10^{-7} \mathrm{P}^{2}, \mathrm{C}_{\mathrm{P}}=87.654 \times 10^{-2}-0.97532$ $\times 10^{-5} \mathrm{P}+1.56533 \times 10^{-10} \mathrm{P}^{2}, \mathrm{D}_{\mathrm{P}}=3.87431+0.96511 \times 10^{-6}$ $\mathrm{P}-0.6542 \times 10^{-8} \mathrm{P}^{2}$, and $\mathrm{E}_{\mathrm{P}}=9432$. A special software is designed to recast $n^{2}(\lambda, P)$ under the form to account for the thermal effects, [11] recalling again Eq. (1) as follows:

$$
\mathrm{n}^{2}(\lambda, T, P, x)=n^{2}(\lambda, T, x) f(\lambda, P)
$$

Where $f(\lambda, P)$ is found to possess the form:

$$
\mathrm{f}(\lambda, \mathrm{P})=1+\mathrm{R}(\lambda, \mathrm{P})
$$

Where:

$$
R(\lambda, P)=\alpha+\beta \lambda+\gamma \lambda^{2}
$$

Where $\alpha=1.2 \times 10^{-3}+1.239 \times 10^{-5} \mathrm{P}-5.2 \times 10^{-9} \mathrm{P}^{2}$, $\beta=2.47 \times 10^{-6}-7.4 \times 10^{-7} \mathrm{P}+3.44 \times 10^{-9} \mathrm{P}^{2}$, $\gamma=6.99 \times 10^{-6}+1.95 \times 10^{-7} \mathrm{P}-1.04 \times 10^{-9} \mathrm{P}^{2}$. The thermal-dependent refractive index $n(\lambda, T, x)$ is cast on the same spirit of [12].

$$
n^{2}(\lambda, T, x)=1+\sum_{i=1}^{3} \frac{A_{i}(T, x) \lambda^{2}}{\lambda^{2}-\lambda_{i}^{2}(T, x)}
$$

Where $A_{i}$ (oscillator strength) are constant related to the number of particles in the material that can oscillate with wavelength $\lambda_{\mathrm{i}}$. Based on the data reported by[13] both the pressure, $\mathrm{P}, \mathrm{MN} / \mathrm{m}^{2}$, and the temperature, $\mathrm{T}$ in $\mathrm{K}$, are correlated to the depth, $\mathrm{D}_{\mathrm{p}}$ in $\mathrm{km}$, as $\mathrm{P}=9.9342 \mathrm{D}_{\mathrm{p}}-0.00912 \mathrm{D}_{\mathrm{p}}{ }^{2}$ $+0.0070732 \mathrm{D}_{\mathrm{p}}{ }^{3}$, where $\mathrm{D}_{\mathrm{p}} \leq 10 \mathrm{~km}$, and $\mathrm{T}=303-3.048$ $\mathrm{D}_{\mathrm{p}}+392.15 \mathrm{D}_{\mathrm{p}}{ }^{2}-542.75 \mathrm{D}_{\mathrm{p}}{ }^{3}$, where $0.0 \leq \mathrm{D}_{\mathrm{p}}, \mathrm{km} \leq 0.5$, and $\mathrm{T}=283.6-10.313 \mathrm{D}_{\mathrm{p}}+4.8422 \mathrm{D}_{\mathrm{p}}{ }^{2}-1.1622 \mathrm{D}_{\mathrm{p}}{ }^{3}$, where $0.5<\mathrm{D}_{\mathrm{p}}, \mathrm{km} \leq 5.5$. Eq. (11) is the corner stone in the 
computation of the dispersion effects and consequently the system capacity. Based on Eq. (1), on can get:

$$
n(\lambda, T, P, x)=n(\lambda, T, x) \sqrt{f(\lambda, P)}=n(\lambda, T x) F(\lambda, P),
$$

but as before $\mathrm{f}(\lambda, \mathrm{P})=1+\mathrm{R}(\lambda, \mathrm{P})$, and $\mathrm{R}(\lambda, \mathrm{P})$ is defined by Eq. (9), then

$$
f(\lambda, P)=[1+R(\lambda, P)]^{0.5}=1.0+0.5 R(\lambda, P) \text {, for } R(\lambda, P) \prec 1.0 .
$$

Based on the models of Refs.[13,14], the total chromatic spreading of a single mode fiber, $\mathrm{D}_{\mathrm{t}}$, depends on $\mathrm{n}(\lambda, \mathrm{T}, \mathrm{P}, \mathrm{x})$ and its four first derivatives n', n", n"', and n"'" w. r. t $\lambda$, respectively, are listed in Ref.[15].

\subsection{Soliton Transmission Technique}

Soliton transmission is an alternative to the usual methods of transmitting a series of amplitude modulated digital pulses through a fiber-optic system. A laser source can generate a series of soliton pulses, $\mathrm{B}_{\mathrm{r} \text { s }}$, Thus the presence of a pulse can mean a "1" and the absence can indicate a " 0 ". Note that solitons must be spaced a certain distance apart to keep them from interfering with each other and that their return to "0" at the end of the pulse makes this signal RZ coded. The repeater spacing " $\mathrm{R}_{s}$ " has no effect, as we get " $\mathrm{B}_{\mathrm{rs}}$ " a distance-free quantity[15] as:

$$
P_{s i o} \tau^{2}=0.597\left(\frac{\lambda_{s i}}{1.54}\right)^{3}\left(\frac{A_{e}}{20}\right)\left(\frac{3.2 \times 10^{-20}}{n_{2 n}}\right)\left|D_{t}\right| \times 10^{6}
$$

Where $\mathrm{P}_{\text {sio }}$ is the initial pulse power of the $\mathrm{i}^{\text {-th }}$ channel in Watt, $\tau$ is the initial optical pulse broadening in psec, $\left|D_{t}\right|$ is the total chromatic dispersion coefficient in psec. $/(\mathrm{km} . \mathrm{nm}), B_{\mathrm{rsi}}$ is the soliton bit rate of the of the $\mathrm{i}^{\text {th }}$ channel, $A_{e}$ is the effective cross section area of the guided mode in $\mu \mathrm{m}^{2}$, and $\mathrm{n}_{2 \mathrm{n}}$ is the nonlinear refractive index coefficient (the Kerr coefficient). For pure silica $\mathrm{n}_{2 \mathrm{n}}=3.2 \times 10^{-20}$ $\mathrm{m}^{2} /$ Watt, while for Germania doped silica $\mathrm{n}_{2}$ is $\mathrm{n}_{2 \mathrm{n}}=$ $3.2 \times 10^{-20}\left(1.0+2.81294 \mathrm{x}-16.6123 \mathrm{x}^{2}+45.9808 \mathrm{x}^{3}\right)$ in $\mathrm{m}^{2} /$ Watt. The effective cross section area of the guided mode $A_{e}$, is:

$$
A_{e}=\frac{\pi}{2}\left(R_{1}^{2}+R_{2}^{2}\right)
$$

where $R_{1}$ and $R_{2}$ are the mode field radii of the two light waves with two wavelengths $\lambda_{1}$, and $\lambda_{2}$ respectively coupled with each other[16] and are given by:

$$
R_{1,2}=\frac{0.21 \lambda_{1,2}}{\sqrt{\Delta n}}
$$

Where $\Delta \mathrm{n}$ is the relative refractive index difference. In the case of a nonlinear dispersive medium, solitary waves (unchanged propagating shape) result from the balance between nonlinearity and dispersion. These solitons represent the natural eigenstates of nonlinear pulse propagation in single mode fibers, and they can easily be excited provided the initial peak power is above certain threshold. Based on the analysis of [17] the peak power is given by

$$
P_{\text {peak }}=\frac{3.09 \lambda_{s i}^{3} A_{e}\left|D_{t}\right|}{4 \pi^{2} c n_{2 n} \tau^{2}}
$$

For light soliton $D_{t}$ must possesses positive value i.e., $\lambda$ is above the zero-dispersion wavelength. It was suggested[17] that the predominance of soliton systems can be enhanced by using optical amplifiers as a means of in-line regenera- tion and pulse reshaping. Based on the analysis of[18], the minimum separation for a stream of soliton pulses to carry useful data is $\tau_{\min }=10 \tau$. This is due to the pulse broadening. The Soliton transmitted bit rate per channel $\left(\mathrm{B}_{\mathrm{rsch}}=1 / \tau_{\min }\right.$.) then, $\tau=1 / 10 B_{\text {rsch. }}$. With soliton bit rate per link $B_{\mathrm{rsl}}=\mathrm{B}_{\mathrm{rsch}}$ $\mathrm{N}_{\mathrm{L}}$.

\subsection{Forward Raman Amplification}

For forward Raman amplification over a transmission distance $\mathrm{L}_{\mathrm{f}}$, the signal power $\mathrm{P}_{\mathrm{si}}(\mathrm{i}=1,2, \ldots, \mathrm{N})$ and the Raman pump power $P_{R}$ are injected at $Z=0.0$ and travel in the $+Z$ direction. The differential equations governing the signals and pump propagation are given by[65].

$$
\begin{aligned}
& \frac{d P_{s i}(Z)}{d Z}=\left[\begin{array}{l}
-\sigma_{s i}+\frac{g_{i}}{A_{e}} P_{R}(Z) \\
+\sum_{j=1}^{i-1} \frac{g_{i j} P_{s j}(Z)}{A_{e}}-\sum_{m=i+1}^{N} \frac{\lambda_{s m}}{\lambda_{s i}} \frac{g_{i m} P_{s m}(Z)}{A_{e}}
\end{array}\right] P_{s i}(Z) \\
& \frac{d P_{R}(Z)}{d Z}=-\left[\sigma_{R}+\sum_{i=1}^{N} \frac{g_{i} \lambda_{s i}}{A_{e} \lambda_{R}} P_{s i}(Z)\right] P_{R}(Z)
\end{aligned}
$$

Where Suffix si referred to the $i^{\text {th }}$ signal in the WDM system, Suffix R referred to the Raman pump, $A_{e}$ is the effective cross section area of the guided mode, $g$ is the Raman gain coefficient due to Raman amplification. It is a frequency dependent parameter, $g_{o}$ is the peak Raman gain coefficient, $g_{i}$ is the Raman gain constant coupling the pump and the $i^{\text {th }}$ signal, $g_{i j}$ is the Raman gain constant coupling the $\mathrm{i}^{\text {th }}$ and the $\mathrm{j}^{- \text {th }}$ signal channels, and $\sigma$ is the total spectral loss $\mathrm{dB} / \mathrm{km}$ (fiber attenuation coefficient) and is given by [20].

$$
\sigma=\sigma_{\mathrm{I}}+\sigma_{\mathrm{IR}}+\sigma_{\mathrm{UV}}+\sigma_{\mathrm{S}}
$$

Where $\sigma_{\mathrm{S}}$ is the scattering loss $=(0.75+66 \Delta \mathrm{n}) / \lambda^{4} \mathrm{~dB} / \mathrm{km}$, $\sigma_{\mathrm{I}}$ is the intrinsic loss $=0.03 \mathrm{~dB} / \mathrm{km}, \sigma_{\mathrm{IR}}$ is the infrared loss $=$ $49 \times 10^{10} \exp (-48 / \lambda) \mathrm{dB} / \mathrm{km}$, and $\sigma_{\mathrm{UV}}$ is the ultraviolet loss $=$ $[0.0132 \mathrm{x} /(1+0.733 \mathrm{x})] \exp (4.9 / \lambda) \mathrm{dB} / \mathrm{km}$, where $\mathrm{x}$ is the mole fraction of $\mathrm{GeO}_{2}$, i.e. percentage of germania-doped silica fiber. Where $\lambda_{\mathrm{s} 1}<\lambda_{\mathrm{s} 2}<\ldots<\lambda_{\mathrm{sN}}$ of the $\mathrm{N}$ channels are equally spaced in frequency domain with channel spacing $\Delta \lambda$. Assuming the polarization of the fiber is maintained. The second term in Eqn. (14) denotes the coupling between the $\mathrm{i}^{\text {th }}$ signal and the pump, the third and the last terms express the cross coupling among the signal channels. To achieve high amplifier gain, the signal frequencies should be chosen so the $g_{i}$ is comparable to $g_{o}$ and $\Delta \lambda$ should not be too large. Therefore $\mathrm{g}_{\mathrm{i}}$ can be much larger than the cross coupling coefficient among the signal channels $g_{i j}$ to reduce cross talk. By applying an equivalent Raman gain constant approximation to all the signal charnels, thus $\mathrm{P}_{\mathrm{R}}(\mathrm{Z})$ and $\mathrm{P}_{\mathrm{si}}(Z)$ are analytically solvable. The analytical expression of $\mathrm{P}_{\mathrm{R}}(\mathrm{Z})$ and $\mathrm{P}_{\mathrm{si}}(\mathrm{Z})$ are obtained as[21]:

$$
\begin{gathered}
P_{R}(Z)=\frac{M e^{-\sigma_{R} z}}{1+B \exp \left[K\left(1-e^{-\sigma_{R} z}\right)\right]} \\
P_{s i}(Z)=\frac{S_{i o} \exp \left[K_{i}\left(1-e^{-\sigma_{R} z}\right)\right]}{\left\{1+B \exp \left[K\left(1-e^{-\sigma_{R} z}\right)\right]\right\}^{\phi_{i j}}} e^{-\sigma_{R} z}
\end{gathered}
$$

Where: $\mathrm{M}=\mathrm{P}_{\mathrm{R}}+\mathrm{P}_{\mathrm{ST}}$ (Forward Raman pumping power + 
Total signals power), $\quad P_{S T}=\sum_{i=1}^{N} \frac{\lambda_{s i}}{\lambda_{R}} P_{s i o}, \quad B=\frac{P_{S T}}{P_{R}}$, $K=\frac{g M}{\sigma A_{e}}, K_{i}=\frac{g_{i} M}{\sigma A_{e}}$, and $\phi_{i}=\frac{g_{i}}{g}$. There are two approaches for the calculation of $\mathrm{g}$. The first one is due to[22]. The employed one is due to the work of[22] where:

$$
g_{i}=g_{i 1}+g_{i 2}\left(\lambda-\lambda_{i}\right)
$$

Where $\mathrm{i}=\{1,2,3,4\}$. In this approach, the signal power is processed on the same spirit of[23] we put:

$$
\begin{gathered}
P_{s i}(Z)=U_{s i}(Z) e^{-\sigma_{s i} Z} \\
P_{R}(Z)=W_{R}(Z) e^{-\sigma_{R} Z}
\end{gathered}
$$

Thus:

$$
\begin{gathered}
\frac{d P_{s i}(Z)}{d Z}=\left[U_{s i}^{\prime}(Z)-U_{s i}(Z) \sigma_{s i}\right] e^{-\sigma_{s i} Z} \\
\frac{d P_{R}(Z)}{d Z}=\left[W_{R}^{\prime}(Z)-W_{R}(Z) \sigma_{R}\right] e^{-\sigma_{R} Z}
\end{gathered}
$$

Also

The maximum repeater spacing $R_{s m}$ is obtained at the condition: $\mathrm{P}_{\mathrm{si}}\left(\mathrm{R}_{\mathrm{sm}}\right) \cong$ minimum available detectable power which occur at amplified spontaneous emission (ASE)[24] as follows:

$$
P_{s i}(Z)=\frac{-\theta_{i} e^{-\sigma_{s i} Z}}{1+\left(1+\frac{\theta_{i}}{U_{s i o}}\right) e^{+\varphi_{i}\left(1-e^{-\sigma_{a} Z}\right)}}
$$

The light signal must be amplified before its level becomes equal or less than that of the ASE thus we have[25]:

$$
\text { With } \quad B_{e f f}=0.5 \sqrt{\pi} \Delta f\left(\frac{P_{R} g}{A_{e} \sigma_{R}}\right)^{-0.5}
$$$$
\mathrm{ASE}=\mathrm{h} \mathrm{f}_{\mathrm{si}} \mathrm{B}_{\text {eff }}
$$

Where $\Delta \mathrm{f}$ is the noise bandwidth, $\mathrm{h}$ is the Planck's constant, and $\mathrm{f}_{\mathrm{si}}$ is the signal frequency. With $\Delta \mathrm{f}=300 \mathrm{GHz}$, the ASE is of order $0.01 \mu$ Watt. Thus, $R_{s m}$ is the solution of[26]:

$$
D_{f} A S E=U_{s i}\left(R_{s m}\right) e^{-\sigma_{s i} R_{s m}}
$$

Where $\mathrm{D}_{\mathrm{f}}$ is a designed factor $\geq 1.0$

\section{Simulation Results and Performance Evaluation}

We have investigated the transmission characteristics of undersea optical fiber cables to handle the product of the transmission bit rate and the repeater spacing for a cable of 36000 channel and multi optical links (40 to 360 link). Two real cases of advanced division multiplexing and advanced transmission method is processed namely soliton with forward Raman amplification technique is applied. The following items are applied in our performance analysis as follows:

a) The total number of channel $\mathrm{N}_{\text {ch.t }}(=36000$ transmitted channels) is divided to subgroups equal to the number of links $\mathrm{N}_{\text {ch.L }}$ where each link will transmit $\mathrm{N}_{\text {ch L. }}=\mathrm{N}_{\text {ch.t. }} / \mathrm{N}_{\mathrm{L}}$.

b) Channels of each subgroup are selected and grouped to be transmitted in each link. As the channels start from $\lambda_{1}=$
$1.45 \mu \mathrm{m}$ up to $\lambda_{2}=1.65 \mu \mathrm{m}$, then the initial channel of subgroup is $\lambda_{\mathrm{i}}$ and the final one is $\lambda_{\mathrm{f}}$ where reduction of four wave mixing (FWM):

$$
\begin{gathered}
\lambda_{\mathrm{i}}\left(\mathrm{J}_{\mathrm{s}}\right)=\lambda_{1}+\left(\mathrm{J}_{\mathrm{s}}-1\right)\left(\lambda_{2}-\lambda_{1}\right) /\left(\mathrm{N}_{\text {ch.t }}-1\right) \\
\lambda_{\mathrm{f}}\left(\mathrm{J}_{\mathrm{S}}\right)=\lambda_{\mathrm{i}}\left(\mathrm{J}_{\mathrm{S}}\right)+\mathrm{N}_{\mathrm{L}}\left(\mathrm{N}_{\text {ch. } \mathrm{L}}-1\right)\left(\lambda_{2}-\lambda_{1}\right) /\left(\mathrm{N}_{\text {ch.t }}-1\right)
\end{gathered}
$$

Where: $J_{\mathrm{s}}$ is the order of a link $(40, \ldots, 360)$. The central channel in each subgroup is $\lambda_{\mathrm{c}}$ and is given by the sum of Eqs. (27) and (28) as the following:

$$
\begin{gathered}
\lambda_{\mathrm{c}}\left(\mathrm{J}_{\mathrm{s}}\right)=0.5\left[\lambda_{\mathrm{i}}\left(\mathrm{J}_{\mathrm{s}}\right)+\lambda_{\mathrm{f}}\left(\mathrm{J}_{\mathrm{s}}\right)\right]=\lambda_{\mathrm{i}}\left(\mathrm{J}_{\mathrm{s}}\right)+0.5 \mathrm{~N}_{\mathrm{L}}\left(\mathrm{N}_{\mathrm{ch} . \mathrm{L}}-1\right) \\
\left(\lambda_{2}-\lambda_{1}\right) /\left(\mathrm{N}_{\text {ch.t }}-1\right)
\end{gathered}
$$

c) To prevent the channel interaction the power of each channel must not exceed $\mathrm{P}_{\text {sio }}$ [27-29] where:

$\mathrm{P}_{\text {sio }} \mathrm{N}_{\text {ch.L }}\left(\mathrm{N}_{\mathrm{ch.L}}-1\right) \Delta \mathrm{f} \leq 500$, Watt.GHz.

With

$$
\Delta f=\Delta \lambda\left|f_{c} / \lambda_{c}\right|=\Delta \lambda\left(\frac{c}{\lambda_{c}^{2}}\right)
$$

d) The summing and the averaging over the core $\left(\mathrm{N}_{\text {ch.t }}\right)$ are process to obtain Figure to estimate the average bit rate spacing, the average bit rate/channels, and finally the average product per channel.

e) The temperature $T_{0}$ (reference one) where $T_{0}=300 \mathrm{~K}$. Thus the cable is designed at $T_{0}$ with squeezed dispersion $D_{t}$, and special design parameters, and installed under water at depth any $D_{p}$.

f) Finally, if the depth $D_{p}$ is changed, consequently, both the temperature $T\left(D_{p}\right)$, and the pressure $P\left(D_{p}\right)$, will be varied according to the previous equations are listed in the above model. Consequently, theses changes will affect both the bit rate and the repeater spacing, i.e., the product.

In the present study, the following numerical data and ranges are processed: Nonlinear coefficient $\mathrm{n}_{2 \mathrm{n}}=3.2 \times 10^{-20}$ $\mathrm{m}^{2} / \mathrm{W}$ of pure silica fiber, total number of transmitted channels $\mathrm{N}_{\text {ch.t }}=36000$ channels, fiber radius, $\mathrm{a}=5 \mu \mathrm{m}$, water surface temperature, $\mathrm{T}_{0}=300 \mathrm{~K}$, number of links, $\mathrm{N}_{\mathrm{L}}, 40 \leq \mathrm{N}_{\mathrm{L}}$ $\leq 360$, the order of link, Js, $1 \leq \mathrm{Js} \leq 360$, water depth, $\mathrm{D}_{\mathrm{p}}$, $0.0 \leq \mathrm{D}_{\mathrm{p}}, \mathrm{km}, \leq 5$, source spectral width $\Delta \lambda=0.1 \mathrm{~nm}$, operating optical signal wavelength, $\lambda, 1.45 \leq \lambda_{\mathrm{s}}, \mu \mathrm{m}, \leq 1.65$, forward Raman pumping power $\mathrm{P}_{\mathrm{R}}=2$ Watt, and forward Raman pumping power wavelength, $\lambda_{R}=1.45 \mu \mathrm{m}$. The causes for investigation are: the water depth, $D_{p}$ (pressure and temperature), the operating wavelength, $\lambda_{\mathrm{s}}$, and the number of link $\mathrm{N}_{\mathrm{L}}$ in SDM. While the effects under investigation are: the soliton bit rate $\mathrm{B}_{\mathrm{rs}}$, and the repeater spacing, $R_{S}$, to squeeze that achieve a squeezed dispersion $D_{t}$ at somewhat depth. Based on the above equations analysis in the basic model, the above set of the operating parameters, the following facts are assured based on the series of the set of the Figures. (1-10) as the following:

i) As shown in the series of Figures. $(1,2)$ have assured that as both number of links in the fiber cable core and undersea depths increase, this results in decreasing of spectral losses for both silica-doped and plastic based submarine fiber links. Moreover plastic fiber link has presented higher spectral losses than silica-doped fiber link. 


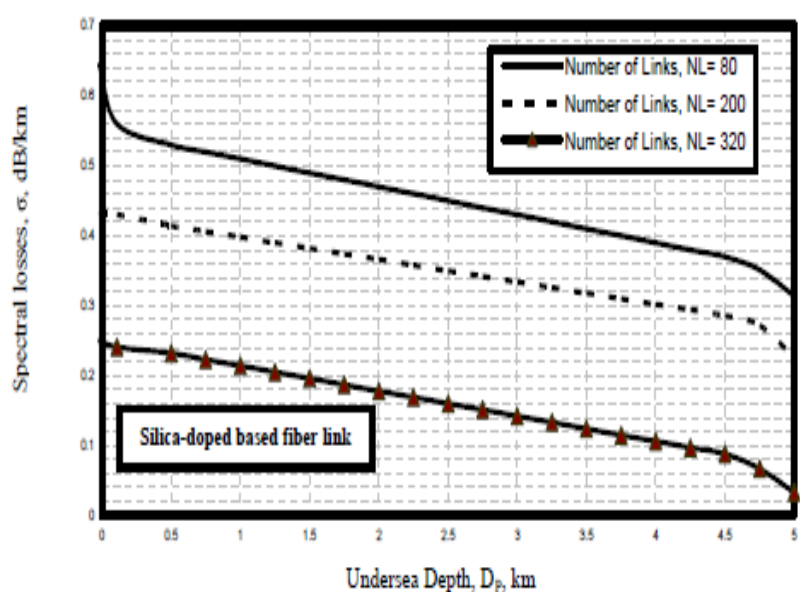

Figure 1. Variations of the spectral losses against undersea depth at the assumed set of parameters.

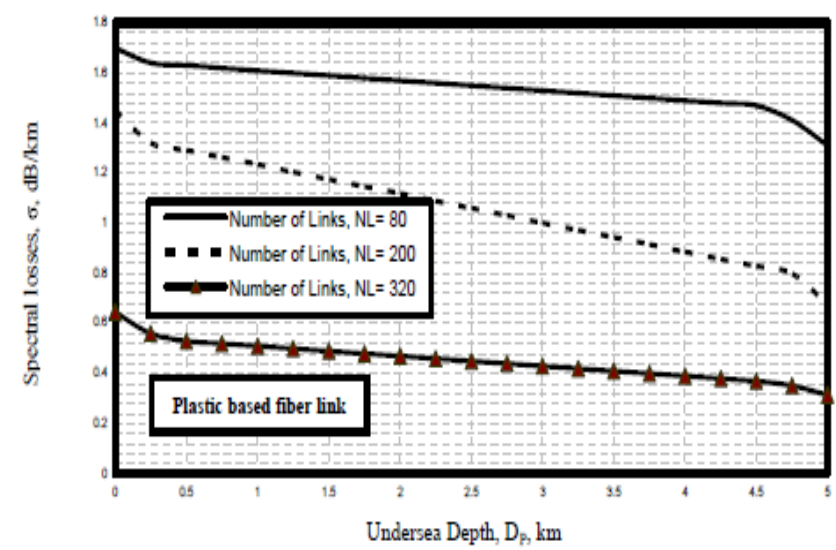

Figure 2. Variations of the spectral losses against undersea depth at the assumed set of parameters.

ii) Figures. $(3,4)$ have demonstrated that as both number of links in the fiber cable core and undersea depths increase, this leads to increase in average repeater spacing for both silica-doped and plastic based submarine fiber links. Plastic fiber link has presented lower repeater spacing than silica-doped fiber link.

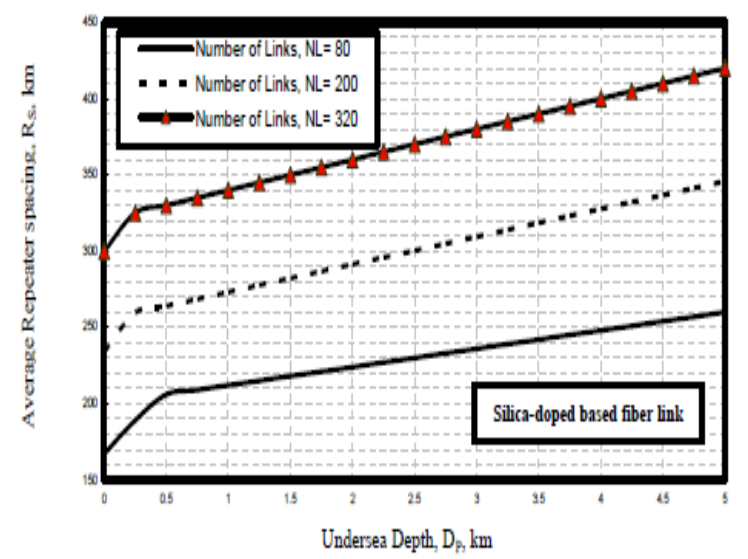

Figure 3. Variations of average repeater spacing against undersea depth at the assumed set of parameters.

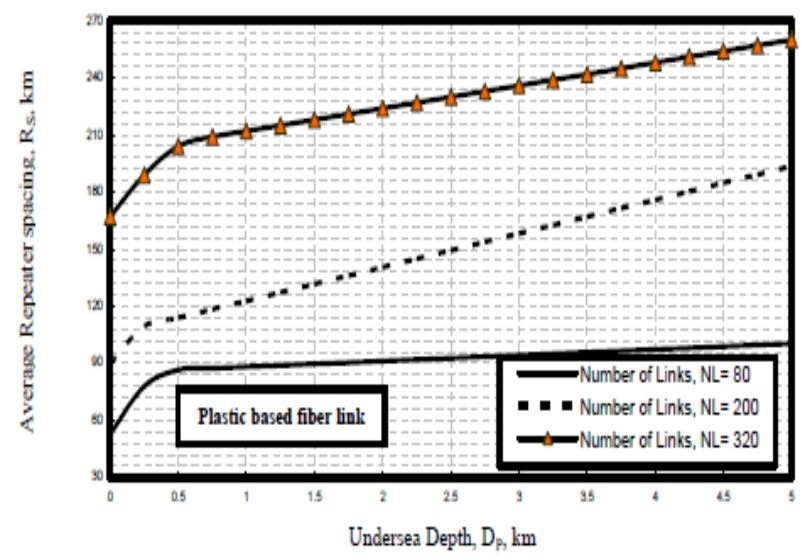

Figure 4. Variations of average repeater apacing against undersea depth at the assumed set of parameters.

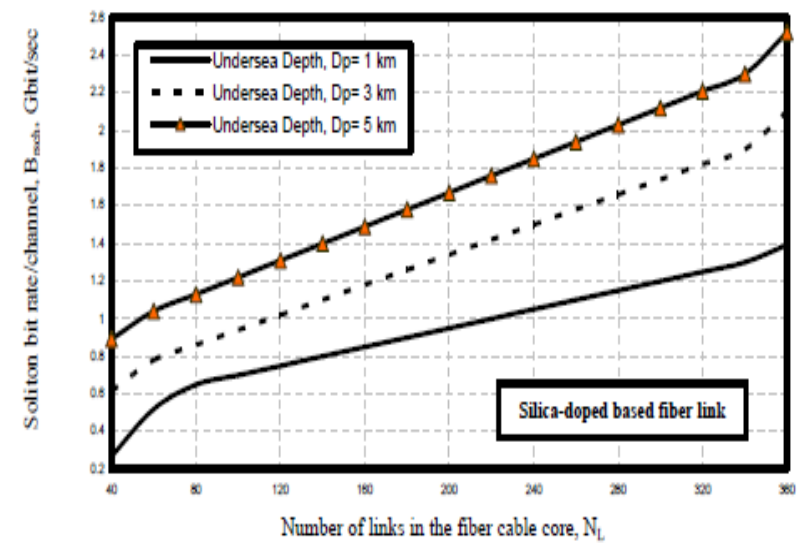

Figure 5. Variations of average soliton bit rate per channel versus number of links at the assumed set of parameters.

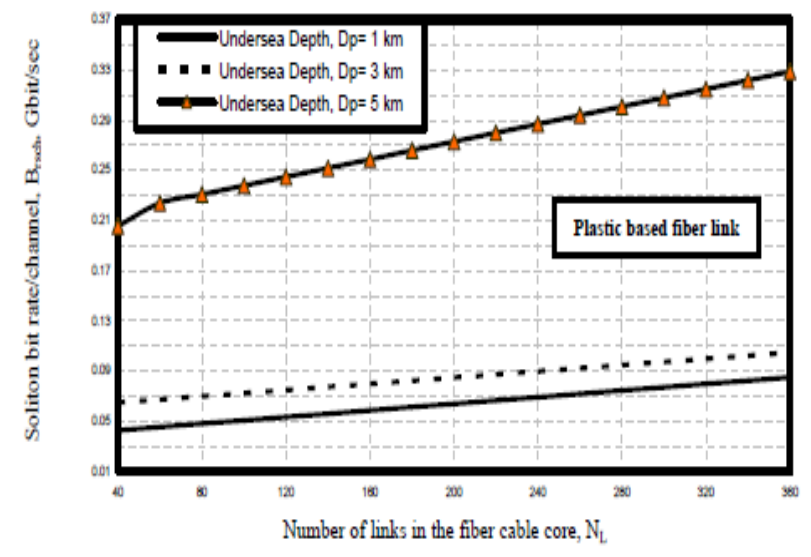

Figure 6. Variations of average soliton bit rate per channel versus number of links at the assumed set of parameters.

iii) As shown in the series of Figures. $(5,6)$ have indicated that as both number of links in the fiber cable core and undersea depths increase, this results in increasing of soliton transmission bit rates per transmitted channel for both silica-doped and plastic based submarine fiber links. As well as plastic fiber link has presented lower transmission soliton bit rates per transmitted channels than silica-doped fiber link. 


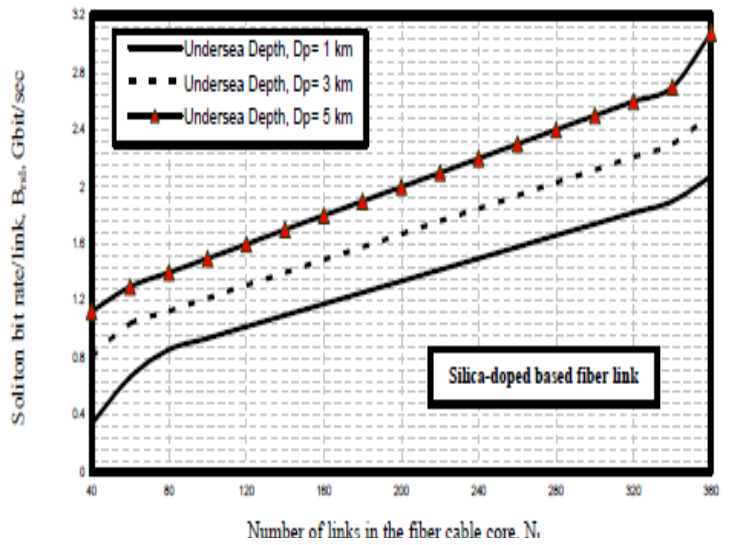

Figure 7. Variations of average soliton bit rate per link versus number of links at the assumed set of parameters.

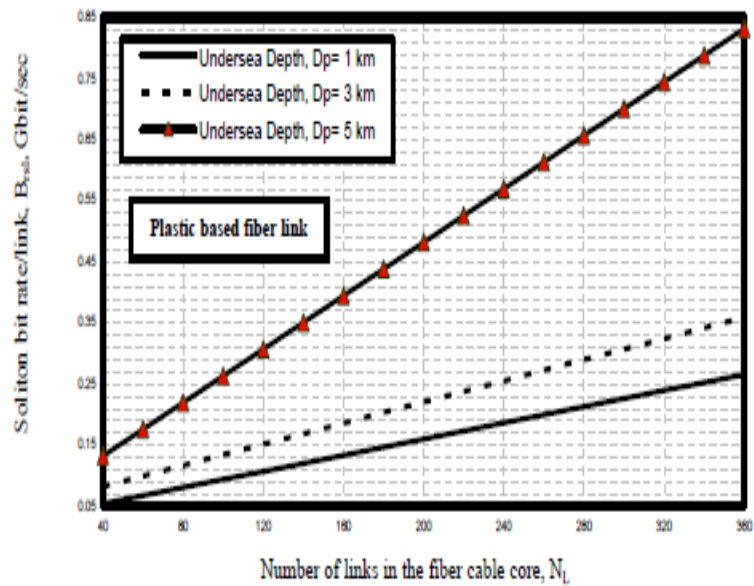

Figure 8. Variations of average soliton bit rate per link versus number of links at the assumed set of parameters.

iii) Figures. $(7,8)$ have demonstrated that as both number of links in the fiber cable core and undersea depths increase, this leads to increase in soliton transmission bit rates per optical link for both silica-doped and plastic based submarine fiber links. As well as plastic fiber link has presented lower transmission soliton bit rates per link than silica-doped fiber link.

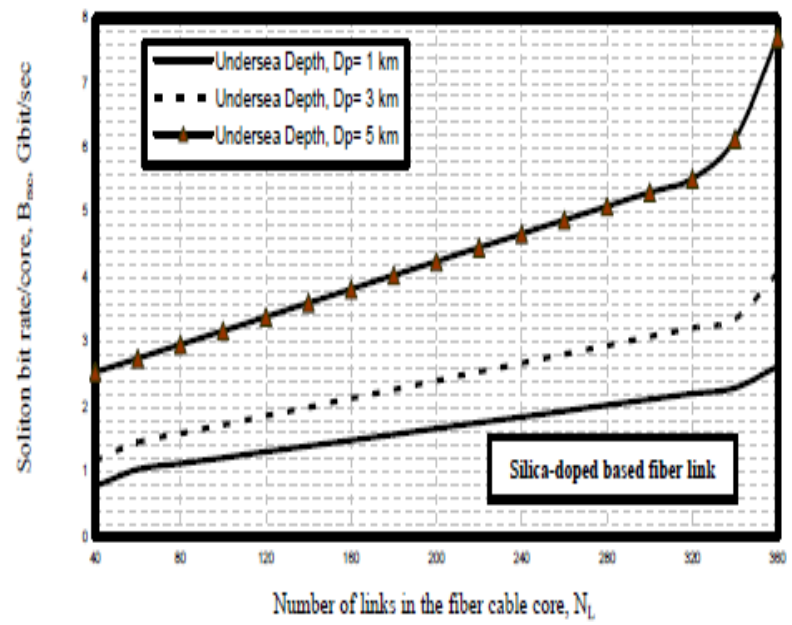

Figure 9. Variations of average soliton bit rate per fiber core versus number of links at the assumed set of parameters.

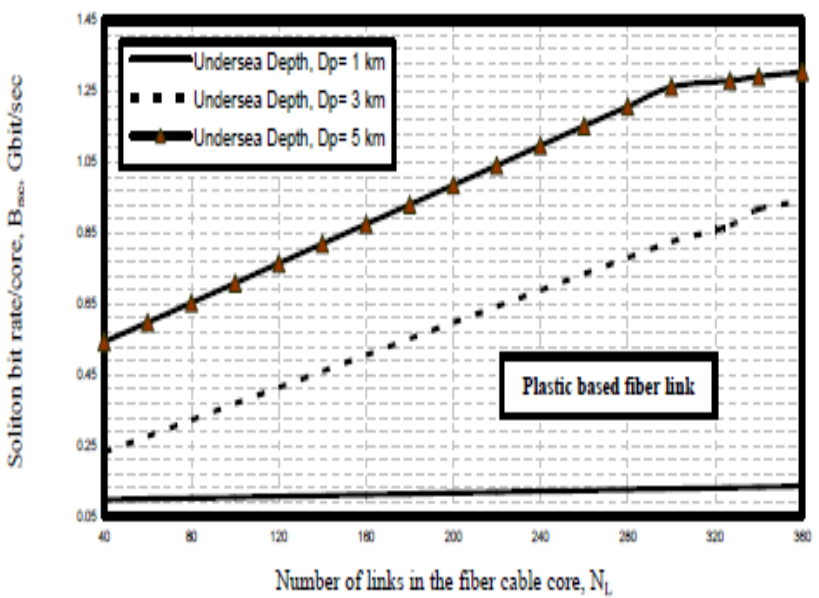

Figure 10. Variations of average soliton bit rate per fiber core versus number of links at the assumed set of parameters.

iv) As shown in the series of Figures. $(9,10)$ have indicated that as both number of links in the fiber cable core and undersea depths increase, this results in increasing of soliton transmission bit rates per core for both silica-doped and plastic based submarine fiber links. As well as plastic fiber link has presented lower transmission soliton bit rates per fiber cable core than silica-doped fiber link.

\section{Conclusions}

The use of single mode fibers (with a core diameter of a few micrometers) was the more promising challenge to face. In addition, further progress in fiber manufacturing (mainly through better material purification) led to evidence of the second window around $1.3 \mu \mathrm{m}$, with an attenuation of about $0.4 \mathrm{~dB} / \mathrm{km}$. Moreover, the bulk silica chromatic dispersion vanishes close to $1.3 \mu \mathrm{m}$; it was therefore possible to propagate high transmission bit rate pulses with minimum pulse broadening. As well as the problem of Ultra Wideband Wavelength Division Multiplexing plus the problem of Ultra Wide Space Division Multiplexing in nonlinear submarine optical cables with conventional Raman amplification techniques are investigated through real transmission technique. The impact of tailoring of chirped pulses of different temporal waveforms is investigated in a normal dispersion fiber. The set of multiplexed signals are tailored in a different a subset to assure approximately the same output level of power to hold the signal to noise ratio at the same level. Moreover, soliton propagation is employed with cohere successive section of alternating dispersion are used also as a technique to manage the dispersion. Distributed "Raman" amplifiers is engaged to maximize the repeater spacing. It is theoretically found that the increased number of links in the fiber cable core and undersea depths, this result in increasing average repeater spacing and then to decrease the spectral losses within silica-doped and plastic based submarine fiber link. Moreover it is evident that the increased of both number of links and undersea depths, this leads to increase in transmission bit rates either per link or per channel and 
then to increase transmission bit rates per fiber cable core. It is indicated that the silica-doped based submarine fiber link has presented lower spectral losses and higher both repeater spacing and soliton transmission bit rates either per link or per channel than plastic links.

\section{REFERENCES}

[1] H. Suzuki, M. Fujiwara, and K. Iwatsuki, "Application of Super DWDM Technologies to Terrestrial Terabit Transmission Systems," J. Lightwave Technol., Vol. 24, No. 5, pp. 1998-2005, May 2006

[2] G. Charlet, and S. Bigo, "Upgrading WDM Submarine Systems to $40 \mathrm{Gbit} / \mathrm{s}$ Channel Bit Rate," Proceedings of the IEEE, Vol. 94, Issue 5, pp. 935-951, May 2006

[3] S. Bigo, "Modeling of WDM Terrestrial and Submarine Links for the Design of WDM Networks," Optical Fiber Communication Conference, 2006 and the 2006 National Fiber Optic Engineers Conference, pp.1-27, 5-10 Mar. 2006

[4] M. Lefrancois, G. Charlet, and S. Bigo,"Impact of Very Large Cumulated Dispersion on Performance of $40 \mathrm{Gbit} / \mathrm{s}$ Submarine Systems Over Non Zero Dispersion Shifted Fibers," Electronics Letters, Vol. 42, No. 3, pp. 174-176, 2006

[5] A. N. Pilipetskii, "High Capacity Undersea Long Haul Systems," J. Selected Topics in Quantum Electronics, Vol.12, Issue 4, pp. 484-496, Aug. 2006

[6] Neal S. Bergano, "Optical Fiber Submarine Cable Systems," J. Lightwave Technol., Vol. 23, No. 12, pp. 4125-4139, Dec. 2005

[7] F. Kerfoot and N. William, "Undersea Fiber Optic Networks: Past, Present, and Future," IEEE J. Selected Areas in Communications, Vol. 16, No. 7, pp. 1220-1225, Sep. 1998

[8] H. Henschel and E. Baumann, "Effect of Natural Radioactivity on Optical Fibers of Undersea Cables," J. Lightwave Technol., Vol. 14, No. 5, pp. 724-731, May 1996

[9] G. Chosh et al., "Pressure Dependent Sellmeier Coefficients and Material Dispersions for Silica Fiber Glass," J. Lightwave Technol., Vol. 16, No. 11, pp. 2002-2005, Nov. 1998

[10] J. Tang "The Shannon Channel Capacity of Dispersion Free Nonlinear Optical Fiber Transmission,” J. Lightwave Technol., Vol. 19, No. 8, pp. 1104-1109, Aug. 2001

[11] J. Tang, "The MultiSpan Effects of Kerr Nonlinearity and Amplifier Noises on Shannon Channel Capacity of a Dispersion Free Nonlinear Optical Fiber," J. Lightwave Technol., Vol. 19, No. 8, pp.1110-1115, Aug. 2001

[12] B. Bakhshi, et al., "First Dispersion Flattened Transpacific Undersea System: From Design to Terabit/s Field Trial," J. Lightwave Technol., Vol. 22, No. 1, pp.233-241, Jan. 2004

[13] C. Rasmussen, et al., "DWDM 40G Transmission Over Trans-Pacific Distance $(10,000 \mathrm{~km})$ Using CSRZ-DPSK, Enhanced FEC, and All-Raman-Amplified 100-km Ultra-Wave Fiber Spans," J. Lightwave Technol., Vol. 22, No. 1, pp.203-207, Jan. 2004

[14] Abd El-Naser A. Mohammed, Abd El-Fattah A. Saad, and Ahmed Nabih Zaki Rashed, "Matrices of the Thermal and Spectral Variations for the fabrication Materials Based Arrayed Waveguide Grating Devices," International Journal of Physical Sciences, Vol. 4, No. 4, pp. 205-211, April 2009

[15] Abd El-Naser A. Mohammed, Gaber E. S. M. El-Abyad, Abd El-Fattah A. Saad, and Ahmed Nabih Zaki Rashed, "High Transmission Bit Rate of A thermal Arrayed Waveguide Grating (AWG) Module in Passive Optical Networks," IJCSIS International Journal of Computer Science and Information Security, Vol. 1, No. 1, pp. 13-22, May 2009

[16] Abd El-Naser A. Mohammed, Abd El-Fattah A. Saad, and Ahmed Nabih Zaki Rashed,"Thermal Sensitivity Coefficients of the Fabrication Materials Based A thermal Arrayed Waveguide Grating (AWG) in Wide Area Dense Wavelength Division Multiplexing Optical Networks," International Journal of Engineering and Technology (IJET), Vol. 1, No. 2, pp. 131-139, June 2009

[17] B. Zhu, et al. "High Spectral Density Long-Haul $40 \mathrm{~Gb} / \mathrm{s}$ Transmission Using CSRZ-DPSK Format," J. Lightwave Technol., Vol. 22, No. 1, pp.208-214, Jan. 2004

[18] M. Murakami, et al., "WDM Upgrading of an Installed Submarine Optical Amplifier System," J. Lightwave Technol., Vol. 19, No. 11, pp.1665-1674, Nov. 2001

[19] Abd El-Naser A. Mohammed, Abd El-Fattah A. Saad, and Ahmed Nabih Zaki Rashed, "Applications of Arrayed Waveguide Grating (AWG) in Passive Optical Networks," IJFGCN International Journal of Future Generation Communication and Networking, Vol. 2, No. 2, pp. 25-36, June 2009

[20] Abd El-Naser A. Mohammed, Abd El-Fattah A. Saad, and Ahmed Nabih Zaki Rashed, "Characteristics of the Fabrication Materials Based Arrayed Waveguide Grating (AWG) in Passive Optical Networks (PONs)," International Journal of Material Sciences Research, Vol. 1, No. 6, pp. 89-97, June 2009

[21] T. Tanaka, et al., "100 GHz Spacing 8 Channel Light Source Integrated With External Cavity Lasers on Planar Lightwave Circuit Platform," J. Lightwave Technol., Vol. 22, No. 2, pp.567-573, Feb. 2004

[22] T. Fujisawa and M. Koshiba, "Time Domain Beam Propagation Method for Nonlinear Optical Propagation Analysis and Its Application to Photonic Crystal Circuits," J. Lightwave Technol., Vol. 22, No. 2, pp.684-691, Feb. 2004

[23] Ming-Sing-Koa and Jingshown Wu, "Extending Transmission Distance of High Density WDM Systems Using Post Transmitter Fiber Raman Amplifiers," J. Lightwave Technol., Vol. 9, No. 3, pp. 394-399, March 1991

[24] Abd El-Naser A. Mohammed, Mohammed M. E. El-Halawany, Ahmed Nabih Zaki Rashed, and Mohamoud M. Eid "Recent Applications of Optical Parametric Amplifiers in Hybrid WDM/TDM Local Area Optical Networks," IJCSIS International Journal of Computer Science and Information Security, Vol. 3, No. 1, pp. 14-24, July 2009

[25] Abd El-Naser A. Mohammed, Gaber E. S. M. El-Abyad, Abd El-Fattah A. Saad, and Ahmed Nabih Zaki Rashed, "Low Loss A thermal Arrayed Waveguide Grating (AWG) 
Module for Passive and Active Optical Network Applications," International Journal of Communication Networks and Information Security (IJCNIS), Vol. 1, No. 2, pp. 27-34, August 2009

[26] Abd El-Naser A. Mohammed, Abd El-Fattah A. Saad, and Ahmed Nabih Zaki Rashed, "Spectral and Thermal Sensitivities of Inorganic-Organic Fabrication Materials Based Arrayed Waveguide Grating (AWG) in Active and Passive Optical Networks (PONs)" International Journal of Intelligent Information Technology Application (IJIITA), Vol. 2, No. 3, pp. 91-98, June 2009

[27] Abd El-Naser A. Mohammed and Ahmed Nabih Zaki Rashed, "Ultra Wide Band (UWB) of Optical Fiber Raman Amplifiers in Advanced Optical Communication Networks," Journal of Media and Communication Studies, Vol. 1, No. 4, pp. 56-78, October 2009

[28] Abd El-Naser A. Mohammed, Mohammed A. Metawe'e, Ahmed Nabih Zaki Rashed, and Mohamoud M. Eid "Distributed Optical Raman Amplifiers in Ultra High Speed Long Haul Transmission Optical Fiber Telecommunication Networks," IJCNS International Journal of Computer and Network Security, Vol. 1, No. 1, pp. 1-8, October 2009

[29] Abd El-Naser A. Mohammed, Mohammed A. Metawe'e, Ahmed Nabih Zaki Rashed, and Amina M. El-Nabawy, "High Transmission Capacity Multiplexing Techniques With Full Bi-directional Pumping Amplification Technique In Advanced High Speed Wired Optical Communication Networks," IJCIIS International Journal of Computational Intelligence and Information Security, Vol. 1, No. 1, pp. 42-56, January 2010 